\title{
Learners With Below Average Reading Abilities
}

\author{
Article by Petrus Johannes Van Staden \\ Clinical Psychology at Texila American University, South Africa \\ Email:vstadenp@gmail.com
}

\section{Introduction}

The purpose of this case study is to serve as a model for educators, family and parents. The study is focus not only on children's reading or level of intellectual but also outline an intervention plan that can be implemented by educators and family members. Further the intervention strategies are to assist a bilingual learner that experiences a low average reading ability.

\section{Background and demographic information}

Lee is a seven-year old female learner at Norkem Park Elementary girl's school. Currently she is in the second grade. Lee is related to the Africa ethnic group and speaks both Afrikaans and Zulu. Zulu is regularly speaking at home amongst her friends and family, however she frequently speaking English, and acquires additional lessons from teachers that assist her twice per week concentrate to develop her reading and spelling skills.

\section{Reason for referral}

Lee undertakes a variety of reading tests to determine whether or not her reading ability was comparable to that of a grade levels standard score. The test that was most suitable in the case of Lee was the AIMS web, TAPS-3 and the WAIT-II. These models were identified by Lee's teacher $\mathrm{Ms}$. $\mathrm{Lu}$, due to her low achievement in a variety of subjects, including, English and Literature and to rule out any possible auditory processing or reasoning problems. These testing instruments were important to consider during the establishment of an academic intervention plan for Lee.

The following Assessments and test were done on Lee taking into consideration the following:

- AIMS web: ability to perform tasks in certain segmentations; reading fluency and reading comprehension.

- TAPS-3: auditory abilities were test through the completion of multiple tasks, including word discrimination, phonological segmentation, number memory, word memory, sentence memory auditory comprehension and auditory reasoning tasks.

- WIST-II: skills in word reading, reading comprehension, pseudo word decoding, numerical operations, math reasoning, spelling etc.

\section{Problem identification/validation}

Lee is an African female learner who speaks both Afrikaans and Zulu. At school Lee speaks English to her teacher and classmates. Her teacher provides instructions in English only. What is interesting is that most of the learners in the school are exclusively Zulu speaking learners. Based on information congregated from her personal file and interviews with her teachers, Lee has no history of any serious medical illness or disability. She looks healthy and active.

Lee has struggled academically, she receive low marks for her assignments, tests and progress report, since her enrollment at Norkem Park girls school. Prior to Lee's enrolment at Norkem Park she was attending a different Elementary school for the first grades. Lee commence at Norkem Park during the middle of the first semester. Lee's teacher Ms Lu made several 
South American Journal of Academic Research

Special Edition May 2016

amendments to assist her. Lee was granted preferential seating in front of the classroom. The teacher has given her one-on-one instructions when possible. None of these preferences have helped Lee, instead she continues receive Cs, Ds and Fs marks.

Lee lives with her mother, grandmother and two brothers in Kempton Park, Gauteng. Lee's mother has full custody of her. The Principle of Norkem Park reported that one of Lee's brothers did not meet the requirements on the entrance exams at Norkem Park. Lee is an energetic child, characterized by her smiling face and her desire to communicate with others freely. Lee further, demonstrates athletic by high-jumping, long jump and during the breaks she is practicing stretching exercises. Although her favourite sports are tennis and football she practicing them every second day and like to watch them on television. She would like to be a sports teacher when she becomes an adult.

\section{Data collection}

It was found that Lee's cumulative file does not contain any information about her performance at school she previously attends. There are also no records regarding past special amenities received from her previous school. Since Lee attends the Norkem Park Elementary girl's school, she has not yet been issued with a report. However, Lee has been issued several progress reports.

In the reports her teacher attests her marks as Cs, Ds and Fs since she entered Norkem Park. After assessing Lee's work, it became clear that she struggles with reading comprehension skills. Although Lee has been able to earn Cs in Math, she still has received Ds and Fs in all other subjects.

\section{Interviews}

Lee stated that she misses her old friend from the previous school and that she does not get along with the kids or adults at Norkem Park. Ms Lu noticed that Lee struggles to make new friends. Ms Lu said Lee often gets into arguments with other learners and her ability to maintain friends at her new school is a huge concern. Ms Lu was asked if she has any knowledge as to why Lee was transferred to Norkem Park, she said that she believes Lee was expelled due to misconduct. Ms Lu also mentions that Lee had already been suspended from Norkem Park, after speaking disrespectfully to the principal of the school.

Both Lee and her teacher stated the social problems that Lee experience, clearly have an influence academically on her. Ms Lu explains that Lee tends to lose her temper often in the classroom when she is having difficulty with a subject. She will hit her head with her hands, slam her pencil on the desk, and "shut down" emotionally. When this happens Lee stops exerting any effort into her learning, resulted in her not understand the lessons being taught. This is clearly that Lee experience great frustration both with her school work and with forming successful interpersonal relationships at school.

\subsection{Observations}

On the day of the test administration Lee complaint and sociable, appeared joyful and excited about meeting the examiner when leaving the classroom for the test. Lee was very inquisitive during the entire testing session and she asks the examiner several personal questions. During the test Lee seems cheerful, very active, frequently standing up, doing push-ups, grabbing the examiners clip board, and scratching the tables. Lee expresses frequent concern about the correctness of her work; she was doing by asking the examiner after each question "is that right"? Although the examiner encourages her, she clearly was not satisfied enough and demanded feedback from the examiner on each question that was very important to her.

In order to gain more information about Lee's learning environment, an instructional observation sheet was used to assess Ms Lu's instructional style. Oral instruction appeared to be 
Ms Lu's main method of teaching her learners. Practically all of Ms Lu's lessons were taught without the use of visual aids or demonstrations. Neither the children, nor Ms Lu was using the white board during class. Instead the lessons were taught orally. This could prove to be problematic for learners who require visual aids and demonstration during instructions. Ms $\mathrm{Lu}$ addressed the learners with individual learning difficulties (such as Lee) by frequently calling on them for answers and visiting their desks frequently to make sure these learners remained on task. $\mathrm{Ms} \mathrm{Lu}$ explained later that it is typical for her to be working closely with Lee during class lessons, calling her and attending to her questions frequently. Ms Lu demonstrated excellent classroom management skills and appeared to create a warm, support environment for her learners.

During the observation of her teacher, Lee was also observed in the classroom. It was found that she interacted with other classmates in a positive manner, but generally did not choose to interact with her peers very often. Lee appears to be quiet and shy, during a free break; she rather sits away from the rest of her classmates. Lee engaged in lessons, writing down answers in her workbook and following along in the reading, at times she turn the pages in her book to different chapters, reading different stories instead of the following lessons. Although Lee's engagement was not always consistent, she still appears to be motivated to produce good work during the lesson and frequently asking the teacher "is this good? Do you like this?” Overall Lee seemed to be adequately engaged and motivated throughout the observation.

\subsection{Test}

The outcome of the following tests and assessments, on the AIMS web, TAPS-3 and the WAIT-II disclose information that was very helpful regarding Lee's areas of academic strength and weakness. Lee scored a high-average range of grade 1 AIMS-web reading analyses. This means that Lee is currently able to read at a normal level among first grade learners. Specifically, Lee scored in the high- average range on the reading fluency analysis and the reading comprehension analysis at the first grade level. When the two readings analyses were given to Lee at the second grade level, she scores in the low average range.

In order to gain more information, phoneme segmentation and a nonsense word fluency analysis were also administered to Lee at the first grade level. Lee earned an average score on the grade 1 nonsense word fluency analyses; however she scored in the bellow average range of the grade 1 phoneme segmentation analyses. Lee achieved an overall score that was in the lowaverage range on the TAPS-III test. Specifically, Lee scored in the low-average of the Phonological Index, demonstrating typical skills in discerning phonological differences and similarities between word pairs, manipulating phonemes within words and blending individual phonemic sounds. Lee scored in the low-average range of the Auditory Memory Index, showing low- normal abilities in retaining and manipulating sequences of numbers, and recalling remote word lists. Although these abilities proved to be adequate, Lee demonstrated general weakness on all the tasks presented by the TAPS-III. On the WIAT-II Lee demonstrated normal cognitive abilities. She achieved a total composite score that was in the low-average range when compared to other children her age. Specifically, she scores in the low-average range of the reading and oral Language Indexes.

On the Mathematics and Written Language Indexes she scored an average. Within the Reading Index, Lee experiences more difficulty on tests of phonological awareness, word recognition, and comprehension of the read content; however she demonstrated personal strength in the area of phonetic decoding. On the Oral Language Index, Lee scored in the low-average range, showing that she struggles with tasks that require her to match pictures with corresponding words or details. 
South American Journal of Academic Research

Special Edition May 2016

Lee also completed the Academic Competence Evaluation Scale - ACES whereby learners are also rated from. Based on her responses, Lee feels that she is most inadequate in the area of interpersonal skills. Although she believes that she struggles with interpersonal skills, study skills, reading skills and critical thinking skills, she feels more confident in her mathematical skills. Lee consistently indicated the frequency level "sometimes" for exhibiting interpersonal skills, engagement and motivation.

\section{Conclusion}

After considering the collected data it would appear that there is reasonable cause for concern regarding Lee's academic performance. Academic intervention also appears to be necessary. Based on the data collected from the AIMS-web tests, the baseline achievement level for Lee is high- grade 1 . Therefore the intervention process would begin with teaching skills at this baseline high- grade 1 level. Tests of Lee's cognitive abilities show that she has the ability to perform at grade level with her peers; however Lee struggles to do so. This might be due to a variety of things. One hypothesis is that Lee could be experiencing difficulty in school due to her recent transfer to Norkem Park.

For Lee to arrive at a new school environment, making new friends and adapt to new classroom expectations was difficult. It is clear from Lee's report that she does not feel comfortable in her new school yet and struggle to get along with other learners at Norkem Park. Another Hypothesis is that Lee cannot adapt to the classroom environment and the kind of teaching style her teacher use. After observing Lee and her teacher, one could see that Lee was unable to follow the teacher's instructions. Lee needed to be reminded regularly by Ms Lu to turn to the correct page in the book and complete the correct work in her book. This indicates that Lee was not able to focus during instructions that might be due to the teaching style of her teacher and also due to carelessness. It is recommended that Lee be assessed by her paediatrician in order to determine whether or not she experience an attention deficit exists.

\section{Intervention model}

\section{Goals for intervention.}

- By the end of September 2015, when given a second grade reading paragraphs, Lee will accurately and fluently read 56 correct words per minute as measured by one minute curriculum-based- measurement reading analysis.

- By the end of September 2015, when given a second grade reading paragraphs, Lee will accurately identify words that complete full sentences and earn 18 responses correct as measured by three minute maze reading analyses.

- By the end of September 2015, Lee will be able to phonemically segment 51 words at the first grade level as measured by one minute phonemic segmentation analysis.

\section{Intervention plan}

- Intervention

The intervention will take place twice per week, on Monday and Thursday mornings an interventionist will implement the intervention plan with Lee on these days in a separate classroom where no other learners are working. During the intervention, visual and kinesthetic exercises and activities will be used. All instructions will be very basic and easy to understand. Based on her indicated areas of academic weakness, the intervention will focus on practice with mainly reading fluency and reading comprehension. While focusing mainly on these two areas, error words that Lee has particular difficulty with will be monitored as the intervention continues. These error words might be sounded out and "clapped out" so that practice with phonemic 
segmentation is also developed during the intervention. As the intervention begins, Lee will practice reading at the high-grade 1 level.

\section{- Methods}

Lee expressed her desire for continuous positive feedback, during both test administration with the examiner and classroom activities with her teacher. For this reason, Lee will be rewarded for her successes throughout the 14 day intervention period. Not only will Lee be rewarded for hard work and improvement on tasks, but she will also be rewarded for simply staying on task and following the rules (since these are both areas of personal weakness for Lee). For example, Lee would be rewarded for every 15 minute period in which she remained seated and on task. Rewards for Lee might include candy, small toys, or breaks when she would be able to move, jump, and do push-ups. In the Journal of Abnormal Child Psychology Douglas and Parry, (1983 pg 313), stated: "an unusual sensitivity to rewards in hyperactive children," Since Lee often has difficulty with staying seated and focused during lessons, rewarding her for accomplishing these tasks is likely to produce positive results.

Using visual and kinesthetic exercises to maintain Lee's attention will be crucial during intervention as well. This means that Lee will review target words in tangible ways. For example, if Lee struggles with reading the word "apple," a beneficial exercise might be for her to colour in a picture of an apple with a correctly spelled label on it. The material and curriculum will consist of activities that utilize interactive elements that provide learning intangible ways, as opposed to the simple oral practice that Lee experienced in her classroom. According to research, "How much a given learner learns in a class is governed in part by that learner's native ability and prior preparation, but also by the compatibility of his or her learning style and the instructor's teaching style" (Felder and Silverman, 1988 pg. 674). It is important for the intervention provider to develop an understanding of Lee's learning style so that instruction can be adapted to best suit her.

The intervention will also contain activities that are uncomplicated and easy to understand. Lee often experiences difficulty focusing. This might be because that she has difficulty understanding directions. It has been shown that, "understanding depends on interaction between elements of the information and diagrams that can reduce cognitive load and enhance understanding” (Marcus, 1996 pg. 49). For this reason, all instructions will be kept basic and easy to understand. Activities will be selected that provide simple instructions. Lee will be asked to perform activities with clear and easy to follow instructions that are provided to her orally and/or visually.

\section{- Materials and Curriculum}

One of the main purposes of this intervention is to increase Lee's reading fluency. One exercise that will provide practice in reading fluency is the Fluency Strategy exercise. This exercise is designed to increase word and paragraphs fluency. First the learner performs a cold reading of the paragraphs and is timed for one minute. The instructor records the errors the learner makes while they read and offers feedback saying, "Yes/No, that word is ......... What is the word? Now please reread the sentence." Next, the instructor models the proper way to read the paragraphs. After the instructor has read the paragraphs to the learner, the learner and the instructor read the paragraphs together, alternating sentences as they read. The learner and the teacher must review the flashcards of error words thoroughly and finally the learner re-reads the paragraphs once more.

Several materials are required for this exercise including a bag, a timer, a red pen, several grade level reading paragraphs, flashcards and a PVC pipe-phone. Practicing repeated reading using the Fluency Strategy exercise is likely to help Lee improve her reading fluency speed. Extensive research has shown that repeated reading has helped many struggling readers succeed. Research suggests that, "repeatedly practicing oral reading of instructional level text with a model 
South American Journal of Academic Research

Special Edition May 2016

and feedback supports growth in oral reading fluency” (Mather and Wendling, 2009, pg. 61).In addition to improving oral reading fluency, repeated reading practice can also help learners to read silently.

Error words should be reviewed at the start of each new session. This can be done by simply pulling error words from a review bag. The game Bingo might also be used to review error words. Prior to playing this game, Lee will need to draw pictures that represent each of the error words that she has difficulty reading. These pictures will be drawn on the back of each error word flashcard. After she has created pictures on each flashcard, the game can begin. To play Bingo, one flash card will be drawn at a time and when the flashcard is drawn, Lee must name the picture and scratch out the word, segmenting the word phonemically. This will allow Lee to practice phonemic segmentation with error words. If Lee has the error word on her Bingo Card, she can place a chip on top of it.

Once Lee connects one row or column she can yell Bingo and win a prize. This game will be very engaging and it will provide a more stimulating form of instruction for Lee The materials required for this activity include flashcards, a bag, Bingo cards, crayons, markers, and Bingo chips. As Lee improves in reading fluency, she is likely to improve in reading comprehension as well. Studies have shown that, "reading fluency includes at least two activities- word identification and comprehension" (Mather and Wendling, 2009, pg, 70). Although reading fluency and reading comprehension skills seem to be correlated, it is not sufficient enough to claim that after working on reading fluency, no work needs to be done in order to build comprehension skills.

To emphasize reading comprehension skills, Lee will be asked several questions about the paragraphs she reads after the Fluency Strategy exercise. In addition to answering comprehension questions about her readings, Lee will also perform a visual arts activity where she must use error words from the paragraphs in new contexts. It has been shown that reading instruction that integrates applying reading comprehension skills in context and using the same words in different contexts may increase reading fluency in a way that also improves reading comprehension specifically (Mather and Wendling, 2009, pg. 70-71). Based on this notion, Lee will be performing an activity where she must take the error words from the Fluency Strategy paragraphs and rewrite a new story using the same words. His story can include illustrations as well. This activity will allow Lee to think about the error words in a different context. This activity requires a story booklet, crayons, markers, and pencils.

\section{- Progress Monitoring Strategy}

Progress will be monitored once per week using first grade reading fluency analyses and first grade reading comprehension analyses provided by AIMS web. Once Lee has earned scores that are in the superior first grade level, second grade reading fluency and reading comprehension probes will be used. Phonemic Segmentation analyses will also be used to monitor Lee's progress throughout the intervention process.

\section{References}

[1.] Chafouleas, Sandra., Daly III, Edward., Skinner H., Christopher. (2005) Interventions for Reading Problems. Designing and Evaluating Effective Strategies. The Guilford Press.

[2.] Douglas B, Virginia I., and Parry K, Penny A. Journal of Abnormal Child Psychology, Vol.11, No. 2, pp.313 -326. Effects of Reward on Delayed Reaction a Time Task Performance of Hyperactive Children. 1983.

[3.] Felder N, Richard M., and Silverman V, Linda K. Learning and Teaching Styles in Engineering Education. Engr. Education, 78(7), 674-681. 1988.

[4.] Marcus S, Nadine Z. Understanding Instructions. Journal of Educational Psychology, v88 n1. p49-63. Mar 1996. 
South American Journal of Academic Research Special Edition May 2016

[5.] Mather M, Nancy L, Wendling P, Barbara J. (2009) Essentials of Evidence-Based Academic Interventions. John Wiley \& Sons, Inc. 